Michael Mallinson: None declared, Sherry Rohekar: None declared, Patrick Leclerc Employee of: Novartis, Julie Schneiderman Employee of: Novartis, Proton Rahman Grant/research support from: Janssen and Novartis, Consultant of: Abbott, AbbVie, Amgen, BMS, Celgene, Lilly, Janssen, Novartis, and Pfizer., Speakers bureau: Abbott, AbbVie, Amgen, BMS, Celgene, Lilly, Janssen, Novartis, Pfizer DOI: 10.1136/annrheumdis-2020-eular.4566

\section{SAT0630-HPR EFFECTS OF GOLIMUMAB ON WORK PRODUCTIVITY AMONG WORK-ACTIVE ANKYLOSING SPONDYLITIS NON-RADIOGRAPHIC AXIAL SPONDYLOARTHRITIS AND PSORIATIC ARTHRITIS PATIENTS IN GREECE: THE 'GO-UP' STUDY}

P. Athanassiou ${ }^{1}$, A. Kotrotsios ${ }^{2}$, I. Kallitsakis ${ }^{3}$, A. Bounas ${ }^{4}$, A. Garyfallos ${ }^{5}$, M. Tektonidou ${ }^{6}$, G. Vosvotekas ${ }^{7}$, E. Petrikkou ${ }^{8}$, G. Katsifis $^{9} .{ }^{1}$ Agios Pavlos General Hospital, Thessaloniki, Greece; ${ }^{2}$ Private Practice, Karditsa, Greece; ${ }^{3}$ Private Practice, Chania, Greece; ${ }^{4}$ Olympion Therapeutirion General Clinic, Patras, Greece; ${ }^{5}$ lppokrateion General Hospital, Thessaloniki, Greece; ${ }^{6}$ Laikon General Hospital, Athens, Greece; ${ }^{7}$ Euromedica General Clinic, Thessaloniki, Greece; ${ }^{8}$ MSD, Medical Affairs, Athens, Greece; ${ }^{9}$ Naval Hospital, Athens, Greece

Background: Golimumab is a tumor necrosis inhibitor (TNFi) approved for the treatment of axial SpA (axSpA) and psoriatic arthritis (PsA), both falling under the Spondyloarthritis $(\mathrm{SpA})$ domain. Real-world data regarding its effect on work productivity (WP) and activity impairment (Al) are limited

Objectives: To assess the impact of golimumab on WP and Al over 12 months of treatment in patients with SpA, overall, and in the axSpA and PsA subpopulations

Methods: A 12-month non-interventional, multicenter, prospective study performed in the routine clinical care. Data were collected at baseline (BL: prior to treatment onset), 3, 6 and 12 months. Adult work-active consented patients with axSpA [ankylosing spondylitis (AS) or non-radiographic axSpA (nr-axSpA)] or PsA, newly initiated on golimumab as per approved label, were concequetively enrolled by 20 sites. Patients prior in $>1$ biologic agent, or switched from another TNFi due to primary non-response or safety were excluded. WP and AI was assessed with the Work Productivity and Activity Impairment: Specific Health Problem (WPAl:SHP) instrument Results: Between Apr-2017 and May-2018, 121 (51: PsA, 70: axSpA) eligible patients (mean age: 45.4 years; $49.6 \%$ males; $69.0 \%$ overweight/obese; median disease duration: 11.3 months), (Figure 1), were enrolled. Median study duration participation: 11.9 months. Overall, $60.3 \%$ of the patients had previously received disease-modifying antirheumatic drugs and $16.5 \%$ biologics. At BL, the mean (standard deviation: SD) DAS28-ESR of the SpA population and PsA and axSpA subpopulations was 4.0 (1.3), 4.5 (1.2), and 3.6 (1.2), while the mean (SD) BASDAl score of patients with axSpA was 5.6 (1.9). At BL 94.1 and $96.7 \%$ of the SpA population reported WP loss and Al due to their SpA respectively, and at 3 months 87.3 , and $88.0 \%$ respectively. In SpA population, the median BL WP loss and AI were $70.0 \%$ and $65.0 \%$ and decreased by a median of $31.4 \%$ and $40.0 \%$ at 3 months, by $44.2 \%$ and $40.0 \%$ at 6 months and by $50.0 \%$ and $50.0 \%$ at 12 months, respectively (Table 1). Improvements in WP loss and Al were noted in patients with PsA, axSpA, AS and nr-axSpA (Table 1). 12-month golimumab retention rate: $91.7 \%$. No new safety signals emerged

Table 1. Decreases from BL at 3,6 and at 12 months in WP loss and overall Al with the WPAI:SHP instrument

\begin{tabular}{|c|c|c|c|c|c|c|}
\hline & \multicolumn{3}{|c|}{ WP loss (\%) } & \multicolumn{3}{|c|}{ Al (\%) } \\
\hline & \multicolumn{3}{|c|}{$\begin{array}{l}\text { Decrease from BL, } \\
\text { median }(n)\end{array}$} & \multicolumn{3}{|c|}{$\begin{array}{l}\text { Decrease from BL, } \\
\quad \text { median }(n)\end{array}$} \\
\hline & 3 months & 6 months & 12 months & 3 months & 6 months & 12 months \\
\hline $\begin{array}{l}\text { Overall SpA } \\
\text { population }^{\mathrm{a}}\end{array}$ & $31.4^{a}(n=102)$ & $\begin{array}{c}44.2^{\mathrm{a}} \\
(n=94)\end{array}$ & $\begin{array}{l}50.0^{a} \\
(n=87)\end{array}$ & $40.0^{a}(n=107)$ & $\begin{array}{c}40.0^{a} \\
(n=101)\end{array}$ & $\begin{array}{c}50.0^{\mathrm{a}} \\
(\mathrm{n}=92)\end{array}$ \\
\hline PsA & $31.4^{\mathrm{b}}(\mathrm{n}=46)$ & $51.4^{a}(n=42)$ & $\begin{array}{c}53.6^{a} \\
(n=40)\end{array}$ & $40.0^{a}(n=47)$ & $50.0^{a}(n=44)$ & $\begin{array}{c}60.0^{\mathrm{a}} \\
(\mathrm{n}=40)\end{array}$ \\
\hline axSpA & $33.0^{b}(n=56)$ & $\begin{array}{l}30.4^{b} \\
(n=52)\end{array}$ & $\begin{array}{l}45.5^{b} \\
(n=47)\end{array}$ & $40.0^{a}(n=60)$ & $40.0^{\mathrm{b}}(\mathrm{n}=57)$ & $\begin{array}{l}40.0^{\mathrm{b}} \\
(\mathrm{n}=52)\end{array}$ \\
\hline $\begin{array}{l}\mathrm{AS}^{\mathrm{c}} \\
\mathrm{nr}-\mathrm{axSp} \mathrm{A}^{\mathrm{c}}\end{array}$ & $\begin{array}{l}25.1(n=35) \\
47.4(n=21)\end{array}$ & $\begin{array}{l}29.9(n=32) 3 \\
55.4(n=20) 5\end{array}$ & $\begin{array}{l}39.8(n=29) \\
53.2(n=18)\end{array}$ & $\begin{array}{l}20.0(n=39) \\
50.0(n=21)\end{array}$ & $\begin{array}{l}30.0(n=37) \\
55.0(n=20)\end{array}$ & $\begin{array}{l}30.0(n=34) \\
50.0(n=18)\end{array}$ \\
\hline
\end{tabular}

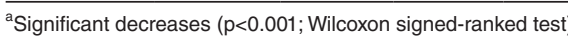

bignificant decreases $(p<0.001$; t-test)

'Statistical significance of the change from baseline was not examined due to the small observations' number

Conclusion: Patients in the SpA population and axSpA and PsA subpopulations treated with golimumab in a routine care setting experienced significant improvements in work productivity and daily activities at 3, 6 and 12 months after treatment initiation
Acknowledgments: The authors thank the following investigators: Ampatziadis E., Voulgari P., Gazi S., Georgiou P., Georgountzos A., Karokis D., Mpotzoris V., Mpournazos E., Sakkas L., Sidiropoulos P., and Vassilopoulos D. The study was Sponsored by MSD, Greece.

Disclosure of Interests: Panagiotis Athanassiou Grant/research support from: MSD, Genesis pharma, Janssen, Consultant of: Roche, Genesis pharma, Janssen, Speakers bureau: MSD, Janssen, Roche, Genesis pharma, Anastassios Kotrotsios Grant/research support from: MSD, Novartis, Roche, Consultant of: Bristol Myers Squibb, UCB pharma, Speakers bureau: Genesis pharma, UCB pharma, MSD Ioannis Kallitsakis Grant/research support from: MSD, Speakers bureau: Genesis pharma, Bristol-Myers Squibb, Andreas Bounas Grant/research support from: MSD,

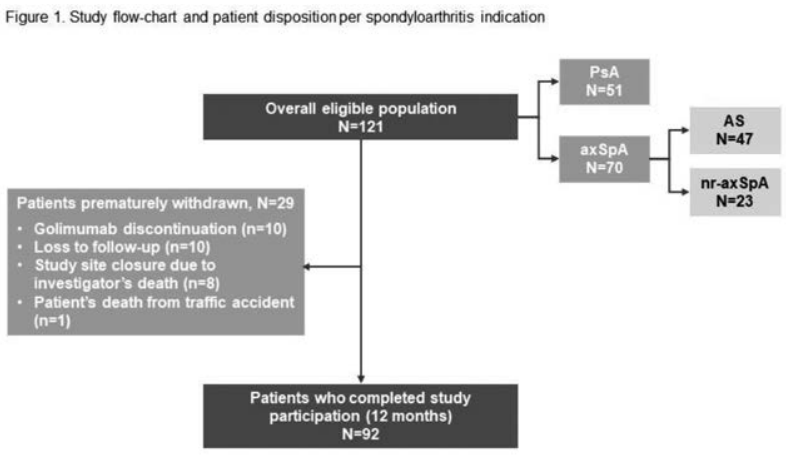

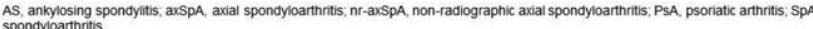

AbbVie, Novartis, Genesis pharma, Consultant of: MSD, Bristol-Myers Squibb, UCB pharma, AbbVie, Speakers bureau: MSD, Bristol-Myers Squibb, Pfizer, Alexandros Garyfallos Grant/research support from: MSD, Aenorasis SA, Speakers bureau: MSD, Novartis, gsk, Maria Tektonidou Grant/research support from: AbbVie, MSD Novartis and Pfizer, Consultant of: AbbVie, MSD, Novartis and Pfizer, GEORGIOS VOSVOTEKAS Grant/research support from: MSD, Janssen, Consultant of: MSD, Novartis, Roche, UCB pharma, Bristol-Myers Squibb, AbbVie, Speakers bureau: UCB pharma, Menarini, Bristol-Myers Squibb, MSD, Evangelia Petrikkou Employee of: MSD, Bristol Myers Squibb, Vianex SA, Gkikas Katsifis Grant/research support from: UCB Pharma, Janssen, Abbvie, Novartis, MSD, Aenorasis, Genesis Pharma, Pfizer, Roche, Consultant of: UCB Pharma, Janssen, Abbvie, Novartis, MSD, Aenorasis, Genesis Pharma, Pfizer, Roche, Speakers bureau: UCB Pharma, Janssen, Abbvie, Novartis, MSD, Aenorasis, Genesis Pharma, Pfizer, Roche DOI: 10.1136/annrheumdis-2020-eular.5572

\section{SAT0631-HPR WHEN CAN I STOP MY STEROIDS? THE PATIENT PERSPECTIVE ON GLUCOCORTICOID USAGE IN ADULT INFLAMMATORY MYOPATHY}

J. Loarce-Martos ${ }^{1}$, J. B. Lilleker ${ }^{2,3}$, E. Alder ${ }^{2}$, J. Goode ${ }^{4}$, H. Chinoy ${ }^{2,5} .{ }^{1}$ Ramón y Cajal University Hospital, Madrid, Spain; ${ }^{2}$ University of Manchester, Centre for Musculoskeletal Research, School of Biological Sciences, Faculty of Biology, Medicine and Health, Manchester Academic Health Science Centre, Manchester, United Kingdom; ${ }^{3}$ Salford Royal NHS Foundation Trust, Manchester Centre for Clinical Neuroscience, Manchester, United Kingdom; ${ }^{4}$ Myositis UK, Southampton, United Kingdom; ${ }^{5}$ Salford Royal NHS Foundation Trust, Rheumatology department, Manchester, United Kingdom

Background: Glucocorticoids (GC) are long established as a first line treatment in patients with idiopathic inflammatory myopathy (IIM), in which high dose, long duration treatment is often required. GC usage is associated with a wide range of adverse effects (AEs). The patient perspective on the risks and benefits of GCs is not well studied and no prior studies assesses this issue in IIM patients (1). Objectives: To describe the perspective of IIM patients on GC treatment. Methods: We deployed an online survey distributed using the Myositis UK page on Healthunlocked.com, an online social network for health, with approximately 450 patients registered. Patients with diagnosed IIM were invited to take part on an anonymised basis. Respondents were asked to grade the severity on a Likert scale (1 to 5) of all AEs experienced in relation to GC. Additionally, respondents were asked to write about their concerns and to rate their overall experience with GC treatment. Results: In total, 122 completed surveys were received. Forty five percen (55/122) of respondents had dermatomyositis, $27 \%$ (33/122) polymyositis, $10 \%$ $(12 / 122)$ anti-synthetase syndrome, 18\% (22/122) other inflammatory myopathies. Seventy-nine percent $(96 / 122)$ of respondents were female and the mean age overall was 50 years (SD [standard deviation] 14). 